\title{
TOBACCO CONTROL
}

A N I NTER NATIONAL JOUR NAL

\section{Editorials}

\section{The news on tobacco control: time to bring the background into the foreground}

Against a background of declining tobacco use and generally positive changes in other heart disease risk factors, a systematic review of 14 multiple risk factor intervention trials for preventing coronary heart disease $\mathrm{e}^{1}$ concluded that reductions in mortality in the intervention groups were insignificant and changes in risk factors only modest, when compared with the reductions also seen in control groups. The Minnesota Heart Health Program reported similar outcomes ${ }^{23}$ and the major multi-community smoking cessation trial, COMMIT ${ }^{45}$ had a similar modest effect on smoking. Compared with typical community health promotion initiatives which operate on token budgets, all of these interventions were large scale, although still were funded with petty cash when compared with the promotional budgets used by the tobacco industry. Favourable improvements in the secular trend for risk factors such as smoking, and programme contamination of control groups have generally been cited as putative explanations of the lack of difference between intervention and control groups, with media leakage-being the most uncontrollable factor-deemed responsible. ${ }^{6}$ Doubtless, some of this leakage involved news coverage of specific interventions intended only for the eyes and ears of the experimental populations. However it is myopic to assume that it is only discrete efforts orchestrated by health agencies leaking into control areas which, in aggregate, constitute the possible forces generating positive secular trends in the wider population.

In a recent issue of Tobacco Control, Melanie Wakefield and Frank Chaloupka called for more attention to the description and quantification of tobacco control "inputs". They noted that the preoccupation with outcomes in evaluation research is often accompanied by overly casual accounts of the policy and intervention variables that are assumed to be the causative factors potentially producing change. In their editorial they argued for the further development of a range of indices to measure the comprehensiveness of tobacco control policies and programmes. They also noted the importance of quantifying and accounting for "environmental" issues such as unpaid media coverage of tobacco issues. This importance cannot be over-emphasised: were it possible to quantify all media coverage of tobacco in societies with 24 -hour access to a multitude of radio, television, internet, and print media, it would almost certainly be the case that, in aggregate, this coverage would routinely eclipse even the most intensive coverage gained through formal public health "campaigns". The current evaluation of ASSIST (American Stop Smoking Intervention Study for Cancer
Prevention), for example, has apparently incorporated over 100000 American newspaper clips on tobacco issues from 1993 to 1999-radio and television, which are more elusive and expensive to capture in research, would have added hundreds of thousands more. And much of this massive reportage is not easily dismissed as inconsequential ephemera: some of the most potent and recalled episodes in the history of tobacco control have been powerful prime-time television documentaries, prolonged episodes such as presidential candidate Bob Dole's foot-in-mouth saga over tobacco policy ${ }^{8}$ and the coverage of legal cases.

Tobacco control has long been highly newsworthy. ${ }^{9}{ }^{10}$ In a recent year, $38 \%$ of all front pages of the Sydney Morning Herald carried at least one health story. ${ }^{11}$ Of these, tobacco stories ranked second after those about health services. From a journalist's perspective, tobacco control offers rich pickings that are likely often to conform with editors' notions of newsworthiness. Our field is resplendent with stories of conflict, corruption, moral rectitude, and reprobation. To the endless fascination of the media, practically every organ of the body can be afflicted by tobacco use and tobacco's stratospheric toll on health lends itself to numerous excursions into quantification rhetoric. ${ }^{12}$ Celebrities' efforts to quit or criticism directed at the influence of their smoking on young people are now routine news events. As the tobacco industry is fond of noting with its unique brand of cynicism, the tobacco epidemic has generated an epidemic of research, much of which is covered by the news media. The media's appetite for villains finds bountiful sustenance in the form of the tobacco industry, which has entered journalistic lexicons as a shorthanding index case device for referencing ethical low life. ${ }^{13}$ Repeated framing of the tobacco industry in such an unfavourable light seems likely to be associated with the community's ranking of tobacco industry representatives' trustworthiness as lower than that of used car salesmen, traditionally the low-water mark in expressions of ethical behaviour. ${ }^{14}$ This in turn may be a critical factor in generating political antipathy toward the tobacco industry in some political circles-as a former president of the American Cancer Society noted: "Most politicians know that you don't stand too close to a pariah in the next photo op."

In addition to news coverage of tobacco, communities are exposed to a wide range of other discourses about smoking in the mass media. Advertisements for shared accommodation commonly list non-smoking as an essential attribute in would-be housemates, ${ }^{15}$ as do "lonely heart" advertisements. Employment advertisements frequently state the 
employers' policies on smokefree workplaces, as does the voluminous advertising for life insurance which almost universally offers large reductions for non-smokers. ${ }^{16}$ Restaurant reviews and guides now often note the smoking policy of each restaurant, as do notices for an as yet small, but increasing, number of music venues.

There is some salutary historical evidence that coverage of smoking in the news media can be influential in promoting smoking cessation. For example, Reid et al ${ }^{17}$ identified unpaid media publicity as the main cause of the $30 \%$ decline in smoking prevalence among British males in the 20 years after the publication of the first report on smoking and health by the Royal College of Physicians of London in 1962. During this time, anti-smoking information and publicity was almost wholly disseminated via news reportage and commentary, with major government health promotion campaigns not starting until the 1980s. On a smaller scale, an American evaluation of a week-long local newspaper series on smoking cessation, which caused around $4 \%$ of readers to quit for at least one week, was calculated as having an impact equivalent to that which would have resulted from the establishment of 380 dedicated cessation clinics. ${ }^{18}$

The way in which the media frame issues for public consumption influences public perceptions, if not behaviour. A good example of this is the growth of public and political concern about illicit drug use. In observing that the issue of drugs being considered by the public as the most important problem facing the United States increased from $5 \%$ in 1985 to $60 \%$ in $1994, \mathrm{Fan}^{19}$ undertook an ingenious study of news coverage from the New York Times, Washington Post, and United Press International newswire from 1985 through 1994. Fan's time series analysis showed that change in this opinion was explained by increases in the news media describing drugs as "a crisis", whereas other types of discussion about drugs contributed negligibly. In the reverse direction, public opinion about drugs was a weak but significant contributor to press coverage. In tobacco control, there is evidence that the extent of news coverage about tobacco issues influences tobacco consumption. Laugesen and $\mathrm{Meads}^{20}$ in New Zealand showed that consumption, measured by weekly purchases of tobacco from a selected number of tobacco outlets, was significantly related to the weekly number of news stories about tobacco, although the effect was short-lived. They estimated that news coverage had approximately the same impact as a $10 \%$ increase in price.

Two papers in this issue of the journal admirably extend the research field of media studies in tobacco control. Kennedy and Bero document the emerging reportage of passive smoking in the American press over 14 years. ${ }^{21}$ Part of their interest lay in examining the process of patronage of industry consultants through which passive smoking continues to be reported as "controversial"-an appellation now seldom used to describe the relationship of active smoking and illness outcomes. Poyant and Siegel's study of the Washington Post's reportage of the American tobacco settlement ${ }^{22}$ uses frame analysis to consider the dominant ways in which the reportage effected closures around what was thereby defined to be at issue in the debate surrounding the settlement. Both papers not only quantify one dimension of the "grey", largely unresearched "inputs" that characterise modern cultural discourse on smoking, but they also offer strategic insights to tobacco control advocates seeking to become more active participants in such discourse.

It is worth reflecting on the intense and prolonged preparation and development that characterises the research development process in public health, when at the end of the day the great majority of published studies resulting are never cited even once, and library copies of the journals in which they are published are seldom, if ever, taken off the shelf. ${ }^{23}$ By contrast, given the opportunity to appear on a national or international television news programme, tobacco control advocates and what they have to say can often be exposed to tens if not hundreds of millions of people. The corresponding preparation for such opportunities is typically fleeting. Studies of media reportage such as the two published in this issue can serve as invaluable background in the project of preparing for framing and reframing in tobacco control debates.

Despite the depressingly common conclusion that many health promotion interventions do not "work", ${ }^{1-5}$ there are too few signs that the tobacco research community has yet taken seriously the implications of the downward secular trend in smoking. In many communities, smoking appears to be declining sometimes desspite many formal interventions. There can be few more important questions than understanding the nature of dominant forces driving this secular trend, and few more perplexing ones than why its study does not command the same or greater research attention as the interest that the study of discrete, sponsored interventions typically generates. The research privileging of sponsored interventions and the comparative neglect of the study of background media "noise" about smoking, such as the examples given earlier, is probably best explained by the political imperatives of evaluation: funding agencies want to know what their investment has achieved and may be less concerned about issues they feel they do not control, or for which they cannot take credit. ${ }^{24}$

Analysis of this vast and relatively neglected potential source of influence on public and political views about tobacco presents many research challenges. Methodological reductionists seeking neat categories to fit seamlessly into their modelling efforts will mostly settle for content analytical approaches, where frequencies can be calculated and hypotheses put to empirical test. But media discourse is inherently qualitative, reflexive and contextual, reflecting the fluid and interactive nature of media discourse. If we wish to understand the process through which the tobacco industry's efforts to frame tobacco control as health fascism jostles for public and political ascendancy with our efforts to frame the industry as run by those with the ethics of a cash register, it will not be sufficient to count just their respective media "hits" and declare a winner. Discourse analysis, ${ }^{25}{ }^{26}$ studies of the ways in which key audiences decode meaning from media performances, and studies in the encoding of news by media workers will all be required. Tobacco Control will welcome submissions that bring these hitherto largely background issues more into the foreground of core research questions being addressed in our field.

SIMON CHAPMAN

Editor

1 Ebrahim S, Smith GD. A systematic review and meta-analysis of randomised controlled trials of health promotion for prevention of coronary heart disease in adults. BMF 1997;314:1666-74.

2 Murray DM. Design and analysis of community trials: lessons from the Minnesota Heart Health Program. Am f Epidemiol 1995;142:569-75.

3 Lando HA, Pechacek TF, Pirie PL, et al. Changes in adult cigarette smoking in the Minnesota Heart Health Program. Am F Public Health 1995;85:2018.

4 Anon. Community intervention trial for smoking cessation (COMMIT). 1. Cohort results from a four-year community intervention Am $\mathcal{f}$ Public Cohort results from a
Health $1995 ; 85$ : $183-92$.

5 Anon. Community intervention trial for smoking cessation (COMMIT). 2. Changes in adult cigarette smoking prevalence. Am f Public Health 1995; 85:193-200.

6 Ebrahim S, Smith GD, Hart JT, et al. Effects of the Heartbeat Wales programme. BMF 1998;317:886.

7 Wakefield M, Chaloupka F. improving the measurement and use of tobacco control "inputs". Tobacco Control 1998;7:333-5.

8 Davis RM. Doling out soundbites in the presidential campaign. Tobacco Control 1996:5:317-39. 
9 Chapman S. The news on smoking: editorial coverage of tobacco and health issues in Australian newspapers, 1987-88. Am f Public Health 1989; 79:1419-20.

10 Menashe CL, Siegel M. The power of a frame: an analysis of newspaper coverage of tobacco issues-United States, 1985-1996. F Health Commun 1998;3:307-25.

11 Lupton D. Medical and health stories on the Sydney Morning Herald's front page. Aust F Public Health 1995;19:501-8.

12 Potter J, Wetherell M, Chitty A. Quantification rhetoric-cancer on television. Discourse \& Society 1991;2:333-65.

13 Christofides N, Chapman S, Dominello A. The new pariahs: discourse on the tobacco industry in the Sydney press, 1993-7. Aust NZ F Public Health 1999;23:233-9.

14 Wakefield M, Miller C, Woodward S. Community perceptions about the tobacco industry and tobacco control funding. Aust NZ f Public Health 1999;23:240-4.

15 Chapman S. Shared accommodation-non-smokers wanted. Tobacco Control 1992;1:248.

16 Howie C. Nonsmokers pay less: the insurance market. Brussels: European Bureau for Action on Smoking Prevention, 1992:49.

17 Reid DJ, Killoran AJ, McNeill AD, et al. Choosing the most effective health promotion options for reducing a nation's smoking prevalence. Tobacco Control 1992;1:185-97.
18 Cummings KM, Sciandra MA, Markello S. Impact of a newspaper mediated quit smoking program. Am f Public Health 1987;77:1452-3.

19 Fan DP. News media framing sets public opinion that drugs are the country's most important problem. Substance Abuse Misuse 1996;31:141321 .

20 Laugesen M, Meads C. Advertising, price, income and publicity effects on weekly cigarette sales in New Zealand supermarkets. $B r \quad f$ Addict 1991;86:83-9.

21 Kennedy GE, Bero LA. Print media coverage of research on passive smoking. Tobacco Control 1999;8:254-60.

22 Poyant JC, Siegel M. The tobacco settlement: an analysis of newspaper coverage of a national policy debate, 1997-98. Tobacco Control 1999;8: $247-53$.

23 Butler D. The writing is on the web for science journals in print. Nature 1999;397:195-200.

24 Chapman S. Unravelling gossamer with boxing gloves: problems in explaining the decline in smoking. BMF 1993;307:429-32.

25 van Dijk TA, ed. Discourse and Communication - new approaches to the analysis of mass media discourse and communication. Berlin: Walter De Gruyter, 1985

26 van Dijk TA. Discourse analysis in the 1990s. Text 1990;10:133-56.

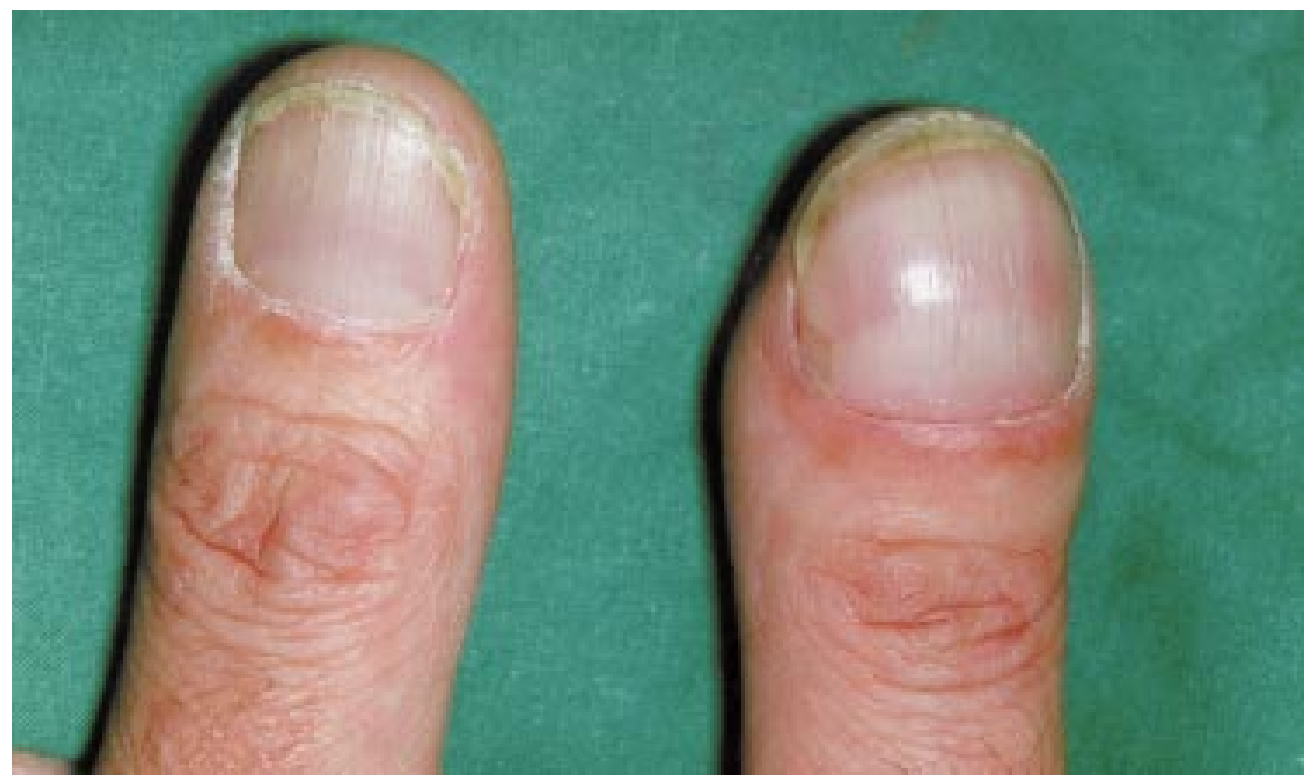

Figure 1 Single digit pseudoclubbing caused by smoking

History: A smoker since childhood, now aged 43 years, presenting for elective surgery, was discovered by his anaesthetist to have "pseudoclubbing' of one thumb. Many years ago he had inserted a coin into a cigarette vending machine. The

machine did not keep to its part of the bargain. With some vigour he pressed the refund button, and was somewhat alarmed as his thumb became stuck in the machine. He was much more alarmed when a painful thud signalled the descent of Something Very Heavy inside the machine onto his thumb. He managed to extract his rapidly swelling digit, and without medical (or legal) advice nursed it for three weeks till the pain subsided. The swelling remains to this day.

Comment: With a careful history taking and examination doctors can explain the connection between smoking and almost anything.

Submitted by fohn Curran, Department of Anaesthesia, Nottingham City Hospital, Nottingham, UK. 